\title{
Macrocytosis in Down's syndrome and during long-term anticonvulsant therapy
}

\author{
R. D. EASTHAM AND J. JANCAR
}

From the Department of Pathology, Frenchay Hospital, Bristol, and Stoke Park Group of Hospitals, Bristol

SYNOPSIS In a group of non-anaemic mentally retarded patients a significant increase in mean red cell volume has been demonstrated in epileptic patients being treated with anti $\vec{z}$ convulsants. The possible sites of interference of anticonvulsants with folate activity in the body, and problems associated with folic acid supplements during anticonvulsant therapy $\vec{\bullet}$ are discussed.

During the survey it was confirmed that the mean red cell volume is abnormally increased in many cases of Down's syndrome.

Long-term anticonvulsant therapy has been shown to be associated with correctable folate deficiency, erythrocyte macrocytosis, and frank megaloblastic anaemia in some cases (Dahlke and Roesler-Mertens, 1967; Hawkins and Meynell, 1958; Klipstein, 1964; Malpas, Spray, and Witts, 1966; Miller, 1968; and Reynolds, Milner, Matthews, and Chanarin, 1966). Past reports of the response of such affected patients with folate supplements have varied from marked clinical improvement on the one hand, to the possibility of increase in both the frequency and severity of epileptic attacks (Chanarin, Mollin, and Anderson, 1958; Druskin, Wallen, and Bonagura, 1962; Hawkins and Meynell, 1958; Reynolds, 1967).

In a dietary experiment in which folate deficiency was induced in normal volunteers it was found that serum folate activity fell below normal after three weeks, hypersegmented polymorphonuclear neutrophils appeared in peripheral blood after seven weeks, whilst macroovalocytosis of the erythrocytes was only detected by about 18 weeks, and frank megaloblastic anaemia was present after 19 weeks (Herbert, 1964).

Since macrocytosis suggests unsuspected folate deficiency in patients treated with anticonvulsants, it was decided to measure the mean red cell size in non-anaemic mentally retarded patients, using Received for publication 9 July 1969. a rapid and accurate electronic particle counte to avoid either tedious visual red cell counting or visual assessment of macrocytosis on stained blood films. Macrocytosis has also been reported in patients with Down's syndrome (Naiman Oski, and Mellman, 1965). Results from patient? with Down's syndrome were therefore included in this study (Eastham and Jancar, 1969) confirming this isolated report.

\section{Methods and Materials}

\section{PATIENTS}

Of a total of 740 non-anaemic mentally retarded patients, aged 21-65 years inclusive, 130 female and 134 male patients were subject to epileptig attacks and were under treatment with ant convulsants, including phenobarbitone, amylo barbitone sodium, primidone, troxidone, pheny? toin sodium or methoin, singly or in variou combinations. Two hundred and nineteen femals and 165 male patients in the same hospitas group were not epileptic subjects and were not treated with anticonvulsants. In addition, there were 47 female and 45 male patients suffering from Down's syndrome who were not epileptis and not being treated with anticonvulsants. The age distributions of the patients in these 
various groups did not show marked differences.

The patients were regarded as non-anaemic if the whole blood haemoglobin concentration fell within the normal range of 13.5 to $18.0 \mathrm{~g}$ per $100 \mathrm{ml}$ for males and 11.5 to $16.4 \mathrm{~g}$ per $100 \mathrm{ml}$ for females, with a mean corpuscular haemoglobin concentration (MCHC) of 32 to $36 \mathrm{~g}$ per $100 \mathrm{ml}$ (Dacie and Lewis, 1963).

\section{BLOOD SAMPLES}

Routine blood samples were collected by venepuncture in plastic syringes into plastic containers with added sequestrene. Haemoglobin concentration, haematrocrit, total white blood cell count, and white cell differential count were completed on each sample. At the same time, whole blood red cell counts were made using a Coulter electronic counter (model D) with a $100 \mu$ orifice. The 1:50,000 dilutions of whole blood in filtered saline were made by two successsive dilutions $(1: 500$ followed by $1: 100)$ using Hook and Tucker autodiluters, and duplicate counts were performed on the final dilutions. (Twelve replicate counts using this system gave a coefficient of variation of $1.83 \%$, and the accuracy of dilution at each stage was checked using p-nitrophenol solution as a reference standard, colour development being by the addition of $40 \% \mathrm{NaOH}$, reading at $420 \mathrm{~m} \mu$ in a Unicam SP 500 spectrophotometer.) From the red cell count and the corresponding haematocrit value, the mean red cell volume for each sample was calculated. The normal range for the MCV in adults is 76-97 $\mu^{3}$ (Dacie and Lewis, 1963).

\section{Results}

The mean cell volume in 384 mentally retarded patients not treated with anticonvulsants was $92.5 \mu^{3}\left(1 \mathrm{SD}=7.38 \mu^{3}\right)$, in 264 mentally retarded patients under treatment with anticonvulsants it was $96.4 \mu^{3}\left(1 \mathrm{SD}=7.78 \mu^{3}\right)$, and in 92 patients with Down's syndrome it was $102.5 \mu^{3}\left(1 \mathrm{SD}=7.87 \mu^{3}\right)$. No significant difference between results in the two sexes was found in each group. All three groups were significantly different from each other $(P<0.001)$.

\section{Discussion}

The findings of Naiman et al (1965) are confirmed, and the erythrocyte cell volume in both male and female patients with Down's syndrome is found to be above the normal range. A possible explanation for such macrocytosis may be that the mean haematocrit in a group of mongoloid patients was found to be larger than that in a $c$ group of non-mongoloid patients, and it was $\cong$ reported that the rates of flux of sodium and potassium across the red cell membrane are greater than normal in mongoloid subjects (Baar and Gordon, 1961).

In both male and female patients there was a significant increase in mean red cell volume when $\bar{c}$ anticonvulsants were being taken, the mean $\underline{O}$ red cell volume in epileptic females being margin- $\frac{\bar{\omega}}{\partial}$ ally above the upper limit of the normal range. $\stackrel{\Phi}{\varnothing}$ Previous reports of macrocytosis resulting from treatment with anticonvulsants have depended on visual assessment of stained blood films? (Klipstein, 1964; Miller, 1968; Reynolds et al, $\overrightarrow{\vec{\omega}}$

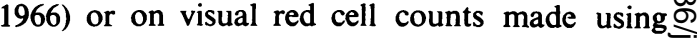
haemocytometers (Hawkins and Meynell, 1958;용 Malpas et al, 1966). In the present study over î 1,000 blood samples were tested. Since each red cell count (involving the electronic counting of 40,000 to 50,000 red cells in $0.5 \mathrm{ml}$ diluted blood) took approximately 12 seconds, with a co-응 efficient of variation of less than $2.0 \%$, noexcessive extra laboratory work was involved, $\bar{z}$ compared with tedious serum folate activity< estimations.

Macrocytosis and reduced serum folate activity tend to develop during long-term treatment with anticonvulsant drugs, and folate supplements result in the return of serum folate activity to normal and in a reduction in macrocytosis (Dahlke and Roesler-Mertins, 1967; Girdwood市 and Lenman, 1956; Hawkins and Meynell, $\stackrel{\varrho}{\rightrightarrows}$ 1958; Ibbotson, 1967). The present study응 demonstrates the appearance of detectable macrocytosis in the absence of anaemia, which may be presumed to be associated with mild folate deficiency.

It has been suggested that similarities in:molecular structure of anticonvulsants and folic acid could account for their interference withô folic acid metabolism (Herbert and Zalusky, 1962), but it is interesting that the addition? of phenobarbitone, phenytoin sodium, and $>$ primidone in vitro do not affect the estimation of folic acid activity by Strept. faecalis (Gird-ñ wood and Lenman, 1956; Klipstein, 1964) It is also worth noting that the growth of $L$. caseio activity is probably a better measure of biologic- $-\omega$ ally active folate derivatives in man (Herbert and Zalusky, 1962). Recent work by Dahlke ando Roesler-Mertens (1967) has shown a furthero possible site of interference by phenytoin sodium.? They have demonstrated that one patient, who developed megaloblastic anaemia but no othero evidence of malabsorption, had impaired folates absorption from the gut whilst he was taking phenytoin sodium, folate absorption returningo to normal when the drug was discontinued, the efficiency of folate absorption being relatedo directly to the time since the last dose of phenytoin sodium.

Opinions on the desirability of repair of folate 
deficiency during long-term anticonvulsant therapy have varied. Apart from the return of the blood picture to normal, folate therapy has been said to result in clinical improvement of patients, with improvement in mental state and in abnormal EEG readings (Druskin et al, 1962; Hawkins and Meynell, 1958; Reynolds, 1967) but with increased frequency or severity of seizures (Chanarin et al, 1958; Reynolds, 1967). The present study, by demonstrating the possibility of detecting early moderate folate deficiency during long-term anticonvulsant therapy in epileptic mentally retarded patients by means of rapid estimations of the mean red cell volume, without requiring serum folate activity estimations (which are very expensive in laboratory working time), should encourage further investigations into this very important problem in the management of epileptic patients. It also makes possible examination of red cell size in Down's syndrome due to trisomy G, mosaicism, or translocation.

We are grateful to Mr W. A. Owen, FIMLT, and the staff under his supervision for continued careful work, to Dr G. Philpot for advice and assistance in the development of the method for checking the accuracy of the autodiluters, and to the staff of the Stoke Park Group for their cooperation and help.
References

Baar, H. S., and Gordon, M. (1963). Kation fluxes in erythrocytes of mongoloids. In Proc. 2nd. int. Congr. ment. Retard., Vienna, 1966, 1, pp. 373-378.

Chanarin, I., Mollin, D. L., and Anderson, B. B. (1958). Folic acid deficiency and the megaloblastic anaemias. Proc. roy. 으 Soc. Med., 51, 757-763.

Dacie, J. V., and Lewis, S. M. (1968). Practical Haematology, $\overrightarrow{\overline{\vec{m}}}$ 3rd ed. Churchill, London.

Dahlke, M. B., and Roesler-Mertens, E. (1967). Malabsorptiono of folic acid due to diphenylhydantoin. Blood, 30, 341-351.

Druskin, M. S., Wallen, M. H., and Bonagura, L. (1962). Anticonvulsant-associated megaloblastic anaemia: response to $\frac{\omega}{7}$ 25 microgm. of folic acid administered by mouth daily. New Engl.J. Med., 267, 483-485.

Eastham, R. D., and Jancar, J. (1969). Macrocytosis in Down's syndrome. Lancet $1,895$.

Girdwood, R. H., and Lenman, J. A. R. (1956). Megaloblastic $\overrightarrow{0}$ anaemia occurring during primidone therapy. Brit. med. J., 1, 146-147.

Hawkins, C. F., and Meynell, M. J. (1958). Macrocytosis and macrocytic anaemia caused by anticonvulsant drugs Quart.J. Med., 27, 45-63.

Herbert, V. (1964). Studies of folate deficiency in man. Proc. roy. Soc. Med., 57, 377-384.

Herbert, V., and Zalusky, R. (1962). Interrelations of vitamin $B_{12}+$ and folic acid metabolism: folic acid clearance studies. i J. clin. Invest., 41, 1263-1276.

Ibbotson, R. N., Dilena, B. A., and Horwood, J. M. (1967). ब Studies on deficiency and absorption of folates in patientso on anticonvulsant drugs. Aust. Ann. Med., 16, 144-150.

Klipstein, F. A. (1964). Subnormal serum folate and macro- $\vec{Z}$ cytosis associated with anticonvulsant drug therapy.
Blood, 23,68-86.

Malpas, J. S., Spray, G. H., and Witts, L. J. (1966). Serumfolic-acid and vitamin $B_{12}$ levels in anticonvulsant therapy. $\vec{\theta}$ Brit. med.J., 1, 955-957.

Miller, D. R. (1968). Serum folate deficiency in children receiving anticonvulsant therapy. Pediatrics, 41, 630-635.

Naiman, J. L., Oski, F. A., and Mellman, W. J. (1965). Phospho-O kinase astivity of erythrocytes in mongolism. Lancet, $1, \leq$ 821.

Reynolds, E. H. (1967). Effects of folic acid on the mental stated and fit-frequency of drug-treated epileptic patients. 응 Lancet, 1, 1086-1089.

Reynolds, E. H., Milner, G., Matthews, D. M., and Chanarin, I.

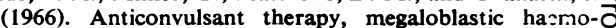
poiesis and folic acid metabolism. Quart. J. Med., 35.Э 521-537.
? 